\title{
Representação Social da Depressão em uma Instituição de Ensino da Rede Pública
}

Depression and Teenagers In a Public Education's Institution

Representación Social de la Depresión en una Institución de Enseñanza de la Red Pública
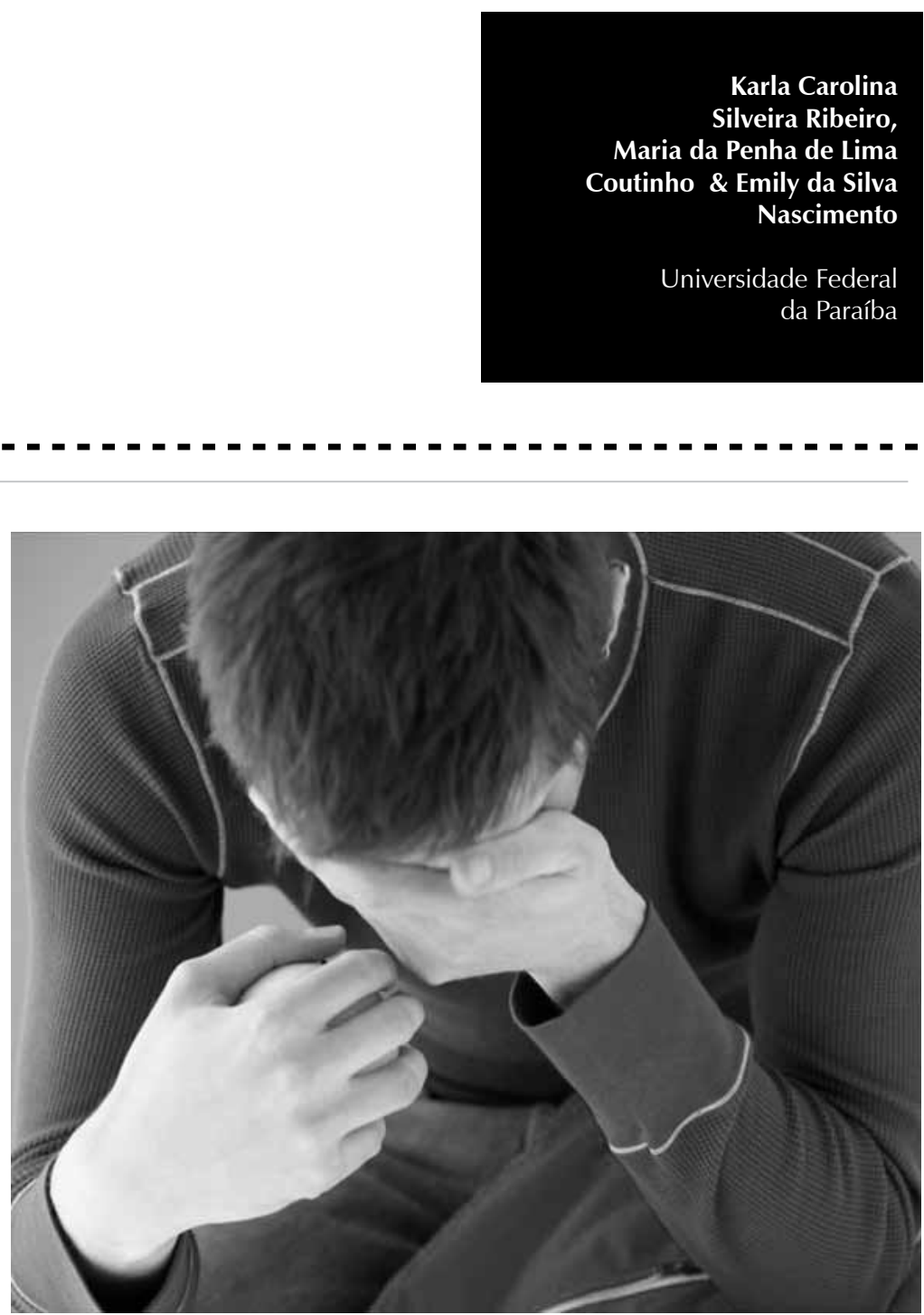
Resumo: Esta pesquisa objetivou apreender as representações sociais da depressão de adolescentes do ensino médio, em uma escola de João Pessoa-PB. Participaram do estudo 276 adolescentes, de ambos os sexos e faixa etária entre 14 e 17 anos. Os instrumentos usados na pesquisa foram: o Inventário da Depressão Infantil (CDI) e a técnica projetiva do desenho-história com tema. Os resultados indicaram que a depressão está associada a quatro aspectos: psicoafetivos, com as subcategorias depressão como sinônimo de tristeza e desilusão amorosa; psicossocial, com a subcategoria dificuldade de relacionamento social, e idéias mórbidas, com a subcategoria ideia de morte e/ou ideação suicida. Essas associações são resultado tanto das vivências dos adolescentes como das informações e representações vinculadas ao seu grupo de pertença, apontando a necessidade de práticas preventivas e educacionais nas instituições de ensino. Palavras-chave: Depressão. Adolescência. Representação social. Desenho-história com tema.

\begin{abstract}
This research aimed to apprehend the social representations of depression held by teenagers in a high school in João Pessoa, PB. The study included 276 adolescents, male and female, aged between 14 and 17 years. The instruments used in the research were the Children's Depression Inventory (CDI) and the projective technique drawing-story with theme. The results indicated that depression is associated with four aspects: psychological and affective, with the subcategories depression as a synonym of sadness and loving disappointment; psychosocial, with the subcategory difficulty of social relationship; morbid ideas, with the subcategory idea of death and/or suicidal ideation. These associations are the result of the adolescents experiences, as the information and representations linked to his group of belonging, pointing the need for preventive and educational practices in the institutions of education. Keywords: Major depression. Teenagers. Social representations. Drawing-story with theme.
\end{abstract}

Resumen: Esta pesquisa tuvo el objetivo de aprehender las representaciones sociales de la depresión de adolescentes de la enseñanza media, en una escuela de João Pessoa-PB. Participaron del estudio 276 adolescentes, de ambos sexos y franja de edad entre 14 y 17 años. Los instrumentos usados en la pesquisa fueron: el Inventario de la Depresión Infantil (CDI) y la técnica proyectiva del dibujohistoria con tema. Los resultados indicaron que la depresión está asociada a cuatro aspectos: psicoafectivos, con las sub-categorías depresión como sinónimo de tristeza y desilusión amorosa; psicosocial, con la sub-categoría dificultad de relacionamiento social, e ideas mórbidas, con la sub-categoría idea de muerte y/o ideación suicida. Esas asociaciones son resultado tanto de las vivencias de los adolescentes como de las informaciones y representaciones vinculadas a su grupo de pertenencia, apuntando la necesidad de prácticas preventivas y educacionales en las instituciones de enseñanza. Palabras clave: Depresión. Adolescencia. Representación social. Dibujo-historia con tema.

Todos os seres humanos são suscetíveis de experimentar emoções desagradáveis, passando por momentos de inquietação. Em referência à adolescência, tem-se esse período como turbulento, uma vez que o jovem atravessa uma série de mudanças físicas e sociais que repercutem também no âmbito psicológico (Aragão, Coutinho, Araújo, \& Castanha, 2009). Ainda que se reconheça que a maioria dos adolescentes possa sentir tristeza e desespero provisório, é certo que transtornos persistentes do humor ocorrem em todas as idades e sob várias circunstâncias (Sadock \& Sadock, 2007).

Logo, este trabalho procura abordar a depressão na adolescência por meio de uma perspectiva histórica e biológica, pois, como ressaltam Bock, Furtado e Teixeira (1999), essa fase seria derivada da estrutura socioeconômica, mas, comumente coincidente com esse período, ter-se-ia a puberdade, com seu aspecto universal, caracterizada pelas modificações visíveis e aparentes, tais como o aparecimento de pelos, o aumento e o desenvolvimento da massa corporal e a menstruação, que, nesses casos, seria um ato biológico ou da natureza (Holmes, 2001). Contudo, tanto a ciência como o senso comum elegem, segundo discute Justo (2005), a adolescência como uma fase de grandes transformações biopsicológicas e sociais. As teorias psicológicas do desenvolvimento dão ênfase à presença 
A adolescência demonstra ser um período vulnerável à instalação da sintomatologia depressiva, já que é marcada por mudança e transição que afeta os aspectos físicos, sexuais, cognitivos e emocionais, caracterizando-se como a fase da reorganização emocional (Assis, Avanci, Silva, Malaquias, Santos, \& Oliveira, 2003). das relações sociais dos adolescentes. Tendo em vista a Lei no 8.069, referente ao Estatuto da Criança e do Adolescente (ECA), o presente estudo vai delimitar o conceito de adolescência tendo como base o artigo 2, que define essa fase como uma variação dos 12 aos 18 anos de idade (Brasil, 1990).

A adolescência demonstra ser um período vulnerável à instalação da sintomatologia depressiva, já que é marcada por mudança e transição que afeta os aspectos físicos, sexuais, cognitivos e emocionais, caracterizando-se como a fase da reorganização emocional (Assis, Avanci, Silva, Malaquias, Santos, \& Oliveira, 2003). De modo geral, os adolescentes se deparam com várias situações novas, como transformações físicas e pressões sociais, que favorecem as condições para que se apresentem flutuações do humor e mudanças expressivas no comportamento. Alguns podem desenvolver quadros francamente depressivos, com notáveis sintomas de descontentamento, confusão, solidão, incompreensão e atitudes de rebeldia (Coutinho, 2005).

Geralmente, durante a puberdade, muitos adolescentes veem as mudanças ocorridas em seu aspecto físico através dos olhos do grupo de iguais, podendo qualquer alteração física resultar em uma redução na autoestima, no desencadeamento de sérias dificuldades de adaptação social e em uma não aceitação pessoal, fatores esses que podem dar origem a sérios conflitos sociais, destacando-se a relação entre os pares, que pode ser fonte de ansiedade e confusão como também os conflitos com os pais devido ao sentimento de ser não compreendido (Bahls, 2001, 2002; Sadock \& Sadock, 2007), daí o fato de este estudo direcionar a depressão desse grupo etário aos aspectos psicossociais envolvidos em suas vivências.
O comportamento de risco na adolescência pode envolver o uso de álcool, de tabaco e de outras substâncias bem como atividade sexual perigosa - em vista do risco de contrair doenças sexualmente transmissíveis - e comportamentos que podem levar a acidentes. As razões para tais comportamentos variam e estão relacionadas, segundo apontam Sadock e Sadock, a uma dinâmica contrafóbica.

Crivelatti, Durman e Hofstatter (2006) destacam que a depressão não diz respeito apenas ao humor deprimido. Corroborando essas premissas, Gunnell (2000) e Coutinho (2005) afirmam que adolescentes deprimidos nem sempre se encontram tristes, mas apresentam-se principalmente irritáveis e instáveis, podendo ocorrer crises de explosão de raiva em seu comportamento. Outras características próprias dessa fase são os prejuízos no desempenho escolar, o isolamento social, as alterações no relacionamento familiar, a baixa autoestima e o aumento de ideias e tentativas de suicídio. Em adolescentes com sintomatologia depressiva, esses pensamentos costumam apresentar alta letalidade e graves problemas de comportamento (Barros, Coutinho, Araújo, \& Castanha, 2006; Coutinho, 2001, 2005). Segundo o DSM-IV - Diagnostic and Statistical Manual of Mental Disorders (APA, 2000), são estes os principais sintomas da depressão em adolescentes: humor deprimido na maior parte do dia, interesses e prazer acentuadamente diminuídos, perda ou ganho significativo de peso sem estar de dieta, insônia ou hipersonia, agitação ou lentidão psicomotora, fadiga, sentimento de inutilidade e pensamento recorrente de morte. Essas manifestações devem comprometer o desempenho e não podem ser explicadas pelo uso de drogas ou por causa ambiental clara, como o luto, por exemplo. Entretanto, as manifestações iniciais podem ser mais 
leves, e nem todos os sintomas podem estar presentes (APA, 2000). Dalgalarrondo (2008) acrescenta que, nos quadros depressivos mais graves, não é incomum ocorrer fixação da atenção em certos temas depressivos, com a concentração em conteúdos de fracasso, culpa, pecado, ruína, etc. Assim, o desempenho prejudicado em tarefas de atenção parece ser proporcional à gravidade do estado depressivo.

A prática clínica tem observado que a probabilidade de manifestação dos sintomas depressivos aumenta com a idade. Por volta dos 10 aos 14 anos, esse percentual chega a triplicar, sendo sua preponderância atualmente uma das mais altas entre essas faixas etárias comparadas à do jovem adulto (American Medical Association (AMA), 2002; Dultra, 2001). Peluso e Blay (2008) realizaram um estudo através do qual averiguaram a percepção da depressão em participantes da cidade de São Paulo/SP, e atribuíram como causas principais da depressão os fatores relativos ao ambiente social e interpessoal, em detrimento das causas de natureza biológica ou de caráter religioso.

Os estudos citados no presente trabalho oferecem uma visão geral sobre a manifestação dos sintomas depressivos nesse período do desenvolvimento humano. Devido à pluralidade e à especificidade do quadro da depressão, o adolescente costuma ser a melhor fonte de informação quanto ao seu sofrimento depressivo, sendo seus colegas e amigos os que mais facilmente reparam nas modificações ocasionadas pela patologia (Assis et al., 2003). Barros, Coutinho, Araújo e Castanha (2006) afirmam que as representações sociais compõem conhecimentos socialmente organizados, que são produzidos por grupos de indivíduos com a finalidade de comunicar-se e de apreender o que lhes desperta a curiosidade. Em se tratando de depressão, os adolescentes, para conviver com essas inquietações, constroem representações sociais que os auxiliam na atribuição de sentido para orientar seus comportamentos no decorrer da experiência com a doença (Coutinho, 2001).

Partindo desse pressuposto, optou-se por ancorar este estudo à teoria das representações sociais (RS), tendo em vista que o homem é um ser ativo dentro do seu meio, como produto e produtor da realidade social (Sá, 1996). Essa abordagem possibilitou o reconhecimento das RS da sintomatologia da depressão no jovem a partir de um conhecimento elaborado e compartilhado pelos próprios adolescentes. Corroborando essa visão, Anadón e Machado (2003) afirmaram que a representação social é a construção de um saber do senso comum elaborado por e dentro das interações sociais, através dos valores, das crenças e dos estereótipos partilhados por um grupo social no que concerne a diferentes objetos, e dá lugar a uma visão comum do mundo. De acordo com essas ideias, Jodelet (2001) acrescenta que essa visão não se constrói no vácuo, mas arraiga-se nas formas e nas normas da cultura e se constrói ao longo das trocas quotidianas; por isso se afirma que a representação social é socialmente construída.

Assim, a representação social pode ser analisada como processo e produto de uma atividade mental pela qual um indivíduo ou um grupo reconstitui o real com o qual ele é confrontado e lhe afere um sentido específico (Abric, 2001). A função essencial da RS, para aqueles que a representam, é transformar aquilo que não é familiar em algo familiar, próximo e prático (Moscovici, 2003). Nesse foco, a elaboração e a sistematização de tais representações implicam, necessariamente, a 
combinação de dois fatores: o primeiro seria o da permanência, que constituiria a rede de representações construída pelo homem ao longo de sua existência, abarcando a sociedade e a cultura a que está vinculada; o segundo fator é o da diversidade, que contém representações subjetivas nos seus aspectos singulares, próprios da vivência de cada pessoa (Coutinho, Gontiés, Araújo, \& Sá, 2003).

Acessar as RS da sintomatologia da depressão é tentar não só compreender as formas que os indivíduos utilizam para criar, modificar e interpretar essa problemática acoplada a sua realidade mas também conhecer seus pensamentos, sentimentos, percepções e experiências de vida compartilhada. Todos esses fatores são destacados nas modalidades diferenciadas de comunicação, de acordo com a classe social a que pertencem, também se prolongam para além das dimensões intrapsíquicas e concretizam-se em fenômenos sociais possíveis de serem identificados e mapeados (Coutinho, 2005). Nesse direcionamento, com o estudo das representações sociais, o conhecimento do senso comum passou a receber a atenção necessária, ou seja, a teoria tem como pressuposto verificar o conhecimento comum produzido através das comunicações por determinados grupos sociais (Nóbrega, 2001).

Portanto, constata-se a necessidade de se pesquisar os fatores psicossociais presentes na depressão de adolescentes. Assim, o objetivo deste estudo foi averiguar, junto a estudantes do ensino médio de escolas públicas, na cidade de João Pessoa/PB, as representações sociais na depressão de adolescentes, pois considera-se que as representações sociais poderão servir para orientar a identificação de práticas sociais que possibilitem implementar programas de políticas públicas, socialmente e culturalmente contextualizadas.

\section{Método}

\section{Campo de investigação}

O presente estudo foi realizado em uma escola da rede pública de ensino médio, localizada no centro da cidade de João Pessoa/ PB. O critério de escolha situou-se no fato de a escola receber alunos de todos os bairros, tanto centrais como periféricos, possuindo assim uma diversidade sociocultural e uma abrangência sociodemográfica dos participantes ali inseridos, A realização deste estudo faz parte de um projeto maior desenvolvido por Coutinho (2001, 2005), no qual a autora pretende mapear a sintomatologia depressiva no contexto escolar público e privado da cidade de João Pessoa/PB.

\section{Participantes}

A amostra foi não probabilística, intencional e acidental. Como critérios de inclusão dos participantes na constituição da amostra, estabeleceram-se: 1) que os participantes deveriam aceitar participar do estudo; 2) cursar do primeiro ao terceiro ano do ensino médio; 3) ter idade máxima de dezessete anos e 4) não apresentar outros sintomas de psicopatologia.

Inicialmente, a pesquisa foi realizada com todos os alunos do ensino médio, 276 adolescentes, sendo 127 do 1 o ano (46\%), 102 do 2 ano (37\%) e 47 do 3 o ano (17\%), para os quais aplicamos o Children's Depression Inventory (CDI) e o desenho-história com tema. Tais adolescentes possuíam faixa etária que variava de 14 a 17 anos $(M=16,34$ anos e $\mathrm{DP}=1,338$ ), e pertenciam a ambos os sexos (44,9\% masculino e $55,1 \%$ feminino). Apesar da não equivalência de gêneros, não se considerou essa diferença como foco para a depressão na adolescência. 
O instrumento CDI foi utilizado para triagem na seleção da amostra. A partir de sua análise, detectaram-se 11 adolescentes (4\% da população) com pontuação acima do ponto de corte; 17 na escala do CDI - indicativo de sintomatologia depressiva - constituindo, assim, a amostra definitiva. Esses adolescentes apresentaram uma pontuação no CDI que variava entre 17 a 29 pontos, o que vem a caracterizar sintomas de depressão moderada.

\section{Instrumentos}

CDI (Inventário de Depressão Infantil)

Foi utilizado o CDI (Children's Depression Inventory), elaborado por Kovacs (1992), que constitui uma adaptação do BDI (Inventário de Depressão de Beck). No entanto, o instrumento utilizado neste estudo foi uma forma ajustada e normatizada por Barbosa, Dias, Gaião e Lorenzo (1996) em uma população brasileira. O instrumento é composto por 20 itens, e cada item consta de três opções de resposta com um valor correspondente $(a=1, b=2, c=3)$, com um ponto de corte (somatório) 17, variando de depressão leve - somatório entre 10 e 16 pontos; depressão moderada - somatório entre 17 e 29 pontos, e depressão severa - entre 30 e 60 pontos, sendo aconselhado para uma faixa etária entre 7 e 17 anos (Cunha, 2001). Esse instrumento tem sido empregado como instrumento de screening na identificação de crianças com alterações afetivas, alterações de humor, capacidade de sentir prazer, funções vegetativas, autoavaliação e outras condutas interpessoais (Coutinho, 2005). O instrumento também continha um questionário sociodemográfico com questões referentes à idade, à série, à turma e ao sexo, que foram essenciais para a compreensão do estudo.
Desenho-história com tema

O segundo instrumento aplicado foi a técnica projetiva desenho-história com tema, desenvolvida a partir do procedimento desenho-história (Trinca, 1976). Essa constitui uma técnica temática e gráfica que possui a finalidade de compreender elementos com vistas à ampliação de dados do dinamismo da personalidade, e pode ser aplicada a todas as faixas etárias, níveis econômicos e mentais (Campos, 2005; Coutinho, 2005). O desenho como técnica projetiva funciona como estímulo da apercepção temática, uma vez que o participante faz um desenho e conta uma história sobre o desenho feito (Winnicott, 1991), além de facilitar o acesso aos conteúdos inconscientes e trazer à tona os conteúdos conscientes (Tsu \& Borges, 1991).

Os desenhos foram selecionados a partir da pontuação do CDI, sendo que os participantes foram os que tiveram pontuação superior ou igual ao ponto de corte. Também foram observados os traços dos desenhos, sua posição na página e seu conteúdo.

\section{Procedimentos de coleta dos dados}

Inicialmente, a pesquisa foi aprovada pelo Comitê de Ética em Pesquisa com Seres Humanos do Centro de Ciências da Saúde da UFPB, no qual foram averiguados os parâmetros éticos, tendo como base a Resolução n 196/96. Para a execução da pesquisa em campo, foram obtidas a autorização da direção da escola pública e a participação voluntária dos alunos. Para tanto, foi realizada uma entrevista com a direção do colégio e com os alunos em sala de aula, esclarecendo-se o intuito da pesquisa; também foram garantidos o anonimato e o 
sigilo das informações coletadas durante o transcorrer do estudo.

Após a confirmação da instituição, foram agendadas visitas à escola para a aplicação coletiva dos instrumentos por quatro pesquisadores previamente treinados. $\mathrm{O}$ estudo foi realizado em dois momentos. Em um primeiro momento, aplicou-se o CDI, na sala de aula, sendo entregue o material aos adolescentes (o questionário), recomendando-se a eles não deixar nenhuma questão em branco e responder apenas a uma alternativa de cada item.

Após o recolhimento dos questionários, seguiu-se a segunda etapa do estudo, com a aplicação do desenho-história com tema, sendo entregue aos alunos folha branca A4 e lápis $n=2$, necessários para a padronização do instrumento. Posteriormente à distribuição do material, foi aplicado o estímulo indutor: "Desenhe uma pessoa depressiva". Ao término do desenho, foi solicitado ao adolescente que desse um título e que contasse uma história sobre o mesmo, com início, meio e fim.

Após todos esses procedimentos, realizou-se o somatório dos itens do CDI, e aqueles jovens que apresentaram uma pontuação superior a 17 pontos foram selecionados para compor a amostra definitiva, com seus respectivos desenhos. A aplicação dos instrumentos transcorreu tranquilamente, não havendo dificuldade quanto à compreensão semântica, como também não foi verificada nenhuma resistência por parte dos adolescentes em participar.

\section{Análise dos dados}

No que se refere à análise dos desenhos, utilizou-se o modelo proposto por Coutinho (2005). Inicialmente, realizou-se uma observação sistemática dos desenhos e temas; em seguida, foram selecionados os desenhos por semelhança gráfica e/ou aproximação dos temas. As histórias foram categorizadas por meio da análise de conteúdo temática, de Bardin (2000), nas seguintes etapas operacionais: leitura flutuante das unidades temáticas, recorte e categorização dessas unidades e, por fim, análise e interpretação dos conteúdos temáticos agrupados por categorias e dos desenhos, por meio do grafismo. É válido salientar que, neste estudo, foi agrupada a categoria temática de acordo com o consenso de quatro juízes especialistas.

\section{Resultados}

A partir da análise realizada nos 11 desenhos dos participantes que apresentaram sintomatologia depressiva (ponto de corte no CDI superior a 17), o material coletado foi coordenado de acordo com as semelhanças gráficas dos desenhos e das histórias comuns.

Os desenhos foram classificados em quatro categorias: 1. Depressão associada aos aspectos psicoafetivos, que correspondeu a 6 desenhos da amostra, e subdivide-se em depressão como sinônimo de tristeza (3 desenhos) e depressão ancorada a desilusão amorosa (3 desenhos); 2. Depressão associada a aspecto psicossocial, para a qual foi encontrada representatividade em 3 desenhos, com a subcategoria dificuldade de relacionamento social, e 3. Depressão associada a ideias mórbidas, que foram representados por 2 desenhos dos 11 selecionados, com a subcategoria ideia de morte e/ou ideação suicida. Por fim, para o presente artigo, foi selecionado o desenho de cada categoria que apresentou uma abrangência maior de sintomas e características categoriais.

1. Depressão associada aos aspectos psicoafetivos 
1.1 Depressão como sinônimo de tristeza

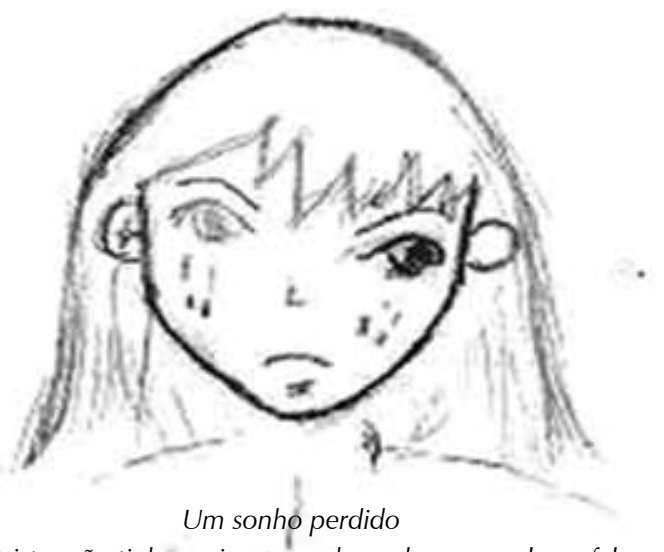

Ela é uma menina muito triste, não tinha amigos e nenhum dos seus colegas falava com ela, ela ficava sempre recolhida e sempre muito triste, até que um dia ela encontrou uma coisa com que se importava muito e ela não se importava com nada, ela ficou feliz enquanto tinha isso, até que um dia ela perdeu aquilo que gostava e então nada voltou a ser como era antes. Até hoje essa menina tem a esperança de tudo voltar ao que era antes, porém triste.

Figura 1. Um sonho perdido.

Os desenhos apresentados nessa subcategoria estão associados aos aspectos psicoafetivos. No desenho acima, sentimentos e afetos são evidentes na expressão facial - olhar e expressão labial - como demonstração do significado latente ao participante, ratificando, assim, um aspecto de tristeza, carência e solidão.

Na figura 1, o participante desenhou apenas um rosto humano, o que pode indicar uma censura ao próprio corpo, confirmada pela presença de franjas no cabelo, sugerindo a tentativa de encobrir um problema, que tanto pode ser de natureza sexual como corporal, fato muito comum entre as adolescentes, uma vez que o corpo idealizado por eles não corresponde ao corpo real (Bahls, 2001). Nesse grafismo, está evidente o sentimento de tristeza, observado nos olhos lamuriosos com presença de lágrimas e na boca em forma de arco, demonstrando, respectivamente, aspiração e expressão chorosa. O contorno do rosto se encontra reforçado, demonstrando tanto dificuldade de inter-relação social assim como insegurança e incapacidade de vencer os problemas, fatos esses que evidenciam desejo de afirmação, caracterizado no esboço das pregas nosolabiais (queixo).

A produção das histórias corrobora os resultados do grafismo, mostrando claramente os elementos de tristeza e debilidade perante o meio:

ela é uma menina muito triste... ficava sempre recolhida... e sempre muito triste... não se importava com nada... perdeu aquilo que gostava... nada voltou a ser como... tem a esperança de tudo voltar a ser como era antes..., porém triste. 
1.2 Depressão ancorada na desilusão amorosa
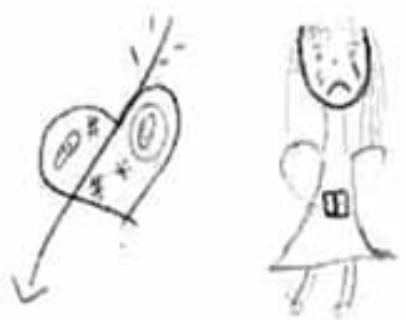

O amor é uma dor:

Quem não tem amor vive assim, os sonhos são todos frustrados e não tem força para viver, precisa apenas de uma solução. O amor é feito para quem tem sorte e quem não dá muito valor tem tudo que deseja, quem dá amor quer receber, mas não tem, só tem ilusão... Sem solução!

Obs: quem tem o que quer agradeça sempre a Deus e se os dois se amam melhor ainda.

Figura 2. O amor é uma dor.

Na figura 2, o desenho se apresenta em tamanho diminuto em relação à folha de papel oferecida para o participante, indicando problemas emocionais e desajuste com o meio, que poderiam ser analisados como decorrentes de uma frustração amorosa, evento esse confirmado pelo desenho à esquerda da figura humana, o qual retrata um coração transposto por uma flecha e que possui ferimentos, nesse caso, simbolizado por curativos. O grafismo apresenta traços evidentes de tristeza, como boca em forma de arco, expressão lamuriosa e presença de lágrimas. Também se evidenciam dificuldade de inter-relação social e insegurança, demonstradas pela boca e rosto em negrito, que podem ser consequência de um modo inseguro de enfrentar a vida, com os olhos representados por um ponto.

Na produção da história, emergiu a mesma temática, que vem corroborar os achados do grafismo, como pode ser observado nos trechos a seguir:

não tem amor... os sonhos são todos frustrados... não tem forças para viver... o amor é feito para quem tem sorte... quem não dar muito valor... tem tudo que deseja... quem dar amor quer receber... mas não tem... tem só ilusão.

2. Depressão associada a aspectos psicossociais

2.1 Dificuldades de relacionamento social
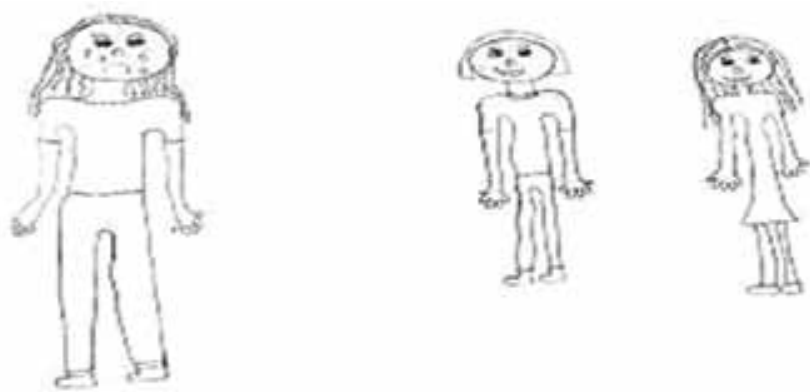

A solidão:

Às vezes uma depressão começa por falta de atenção das pessoas próximas, por timidez. É importante notar se as pessoas ao seu redor, estão tristes e isoladas, e tentar ajudá-las, conversando chamando para sair.

Figura 3. A solidão. 
Na figura 3, a falta de amizade ou de companhia de seus iguais aparece representada no grafismo pelo distanciamento entre as figuras, sendo que as duas figuras humanas à direita apresentam mais proximidade entre si, tendo como referência o desenho da figura depressiva, que mantém uma distância considerável das demais.

O ser depressivo retratado no grafismo, em oposição às outras figuras que possuem um aspecto facial de alegria, apresenta olhos oblíquos para baixo, demonstrando debilidade consciente e fraco controle diante do seu meio social, reforçados pela presença de lágrimas e pela boca em forma de arco, sinônimos de expressão lamuriosa e tristeza.

Os relatos das histórias comprovam os resultados do grafismo, destacando-se a solidão como mensagem central dessa categoria:

falta de atenção das pessoas próximas... timidez... importante notar se a pessoa... ao seu redor... estão tristes... isoladas... tentar ajudá-la... conversando... chamando para.

3. Depressão associada a ideias mórbidas

3.1 Ideia de morte e/ou ideação suicida

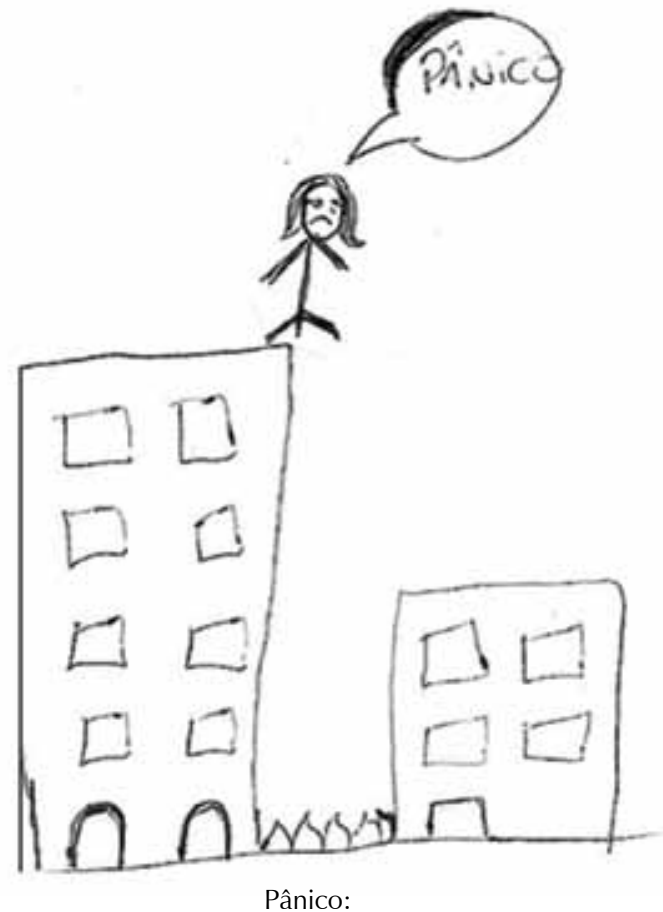

Muitas pessoas com depressão acham que a vida chega ao fim, e acaba com a própria vida. "Nada é impossível".

Figura 4. Pânico.

A depressão associada à ideia de morte se faz presente no grafismo, retratando uma jovem em cima de prédio, com ideação suicida e traços tristes. No esboço, a localização da figura no canto superior esquerdo da página indica fuga ou desajuste do indivíduo ao meio, introversão, tendência a manter-se alheio e inacessível às situações, o que também é evidenciado pelo tamanho diminuto do desenho em relação à página. 
No que se refere à figura humana, percebe-se uma relação desproporcional (aumentada) do tamanho desta em relação ao cenário, evidenciando o desejo de ser observada e de obter atenção. No desenho (ser depressivo), os olhos são esboçados por um ponto, demonstrando um aspecto regressivo na maturidade afetiva, e a boca foi desenhada em forma de arco, ratificando um sentimento de tristeza.

Na produção da história, emergiu a mesma temática, que pode ser observada no trecho a seguir:

Muitas pessoas com depressão... acha que a vida chega ao fim... acaba com a própria vida.

\section{Discussão}

Devido à presença de fatores psicossociais da sintomatologia depressiva entre os adolescentes inseridos no contexto do ensino médio, pode-se considerar que os objetivos desta investigação foram alcançados. Salienta-se que a utilização de uma abordagem multimétodos se mostrou adequada para apreender as categorias inerentes às representações sociais dos atores sociais desta pesquisa.

Um dos primeiros pontos a se analisar é o índice de sintomatologia depressiva apresentada por essa amostra. Entre 276 adolescentes, 11 deles apresentaram sintomas, o que caracteriza $4 \%$ da amostra. Esses dados, ao serem confrontados com pesquisas realizadas no Nordeste por Coutinho (2005), demonstram um baixo nível, tendo em vista que a autora encontrou índices de $11 \%$ em capitais nordestinas, como João Pessoa e Recife. Entretanto, devemos observar que esses participantes obtiveram pontuações no questionário que variaram de 17 a 29 pontos, o que revela sintomas de depressão moderada, apresentando, no repertório de queixas, quatro ou mais sintomas na classificação do DSM-IV (APA, 2000). Esses sintomas ocasionam apatia nas atividades diárias, aumentando a possibilidade de pensamentos mórbidos e de tentativas de suicídio entre esses jovens. Observa-se, portanto, que as representações reveladas pelos participantes estão diretamente associadas aos seus sintomas e vivências, o que possibilitou uma visão singular não só da sua realidade e relações sociais como também da interpretação que os adolescentes deram a esses acontecimentos.

Ao se analisar o resultado postulado, percebe-se que, na adolescência, diversos fatores contribuem para o aparecimento dessa patologia. Nesse contexto, os sentimentos de tristeza, o final de relacionamentos amorosos, o isolamento e a ideação suicida demonstraram serem pilares fundamentais para a compreensão dos fatores psicossociais desencadeantes desse transtorno. Na primeira categoria que emergiu a partir dos desenhoshistória com o tema depressão associada aos aspectos psicoafetivos, a tristeza e a desilusão amorosa são apresentados como fatores que caracterizam essa classe. No que se refere à tristeza, a expressão gráfica apresentou traços faciais sérios, apreendidos pela presença de lágrimas, que seriam traços representativos associados a situações e vivências conflituosas (Coutinho, 2001). Bahls (2002) relata que as novas relações sociais dos adolescentes, notadamente com os pais, podem acarretar o aparecimento de sentimentos de não compreensão; assim também o grupo de iguais pode ser forte fonte de ansiedade e confusão, gerando tristeza aparente e sentimentos de baixa autoestima. 
Em pesquisas realizadas sobre a temática da depressão com adolescentes de ambos os sexos em escolas públicas e privadas na cidade de João Pessoa/PB por Barros (2005), também emergiu a depressão associada ao sentimento de tristeza. Esse fato pode ser evidenciado pela relação existente, no senso comum, de tristeza com depressão. A depressão é confundida com emoções circunstanciais devido a contextos propícios, tais como luto, abandono ou divórcio dos pais, sem ser considerado o tempo de permanência desse sentimento e comportamento. Corroborando esse resultado, percebemos que o sentimento de tristeza é apresentado como fator secundário em relação às demais categorias presentes neste estudo, o que demonstra, assim, a relação existente entre senso comum e representações dos púberes.

No que se refere à desilusão amorosa, Newcombe (1999) apresenta um aspecto factual da adolescência: o aumento de interesse pelo sexo oposto, quando os jovens procuram intimidade emocional. Relações amorosas e interesse sexual na adolescência são primordiais para a formação da identidade do indivíduo, uma vez que os relacionamentos românticos oferecem um cenário no qual os adolescentes podem fazer testes de identidade e observar as consequências de escolhas experimentais de identidade nas relações com seus parceiros. Relações frustrantes e rompimentos traumáticos podem provocar, nesse período de desenvolvimento, dificuldades de relacionamento, retraimento social, baixa autoestima, insegurança e frustração, podendo promover, assim, um quadro depressivo (Newcombe, 1999).

Nessa perspectiva, a relação do adolescente com o meio social caracteriza a segunda subcategoria - depressão associada a aspectos psicossociais - principalmente às dificuldades de relacionamento social. O jovem, ao não se adaptar ao meio por dificuldades familiares, por problemas biológicos e pelo término de relacionamento, etc, tende a se isolar, apresentando sentimentos de inferioridade e de baixa autoestima. Nessa subcategoria, os desenhos e as histórias demonstraram dificuldade de relacionamento entre seus pares. Na fase da adolescência, há maior envolvimento do jovem com o grupo. Os companheiros têm um papel importante no desenvolvimento psicológico e social dos púberes, e quando um jovem apresenta comportamentos de retraimento ou de distanciamento de seu círculo de convivência, isso pode ser um indicativo de sintomatologia depressiva. Em pesquisa realizada por Monteiro, Coutinho e Araújo (2007) com estudantes do ensino médio, os mesmos se consideravam sozinhos, e chatos, e tal fato provavelmente se deve à baixa autoestima que comumente é encontrada no cotidiano das pessoas com sintomatologia depressiva. Segundo Kazdin e Marciano (1998), mais de $80 \%$ dos jovens deprimidos apresentam perda de energia, apatia e forte desinteresse, isolamento e dificuldade de concentração, entre outros sintomas.

Na adolescência, há a necessidade do púbere de ser notado, de sentir-se parte do seu meio social. Há também uma transformação na convivência social; eles começam a se relacionar com turmas e a exercitar sua possibilidade de relacionamento com os outros. Como em todas as outras situações da vida do adolescente, enfrentar essa nova situação desperta medo e receios, ao mesmo tempo em que ocasiona o desejo de conhecer, de buscar o novo e de conseguir se relacionar com os demais (Brêtas, 2003). Confirmando esses resultados, Papalia e Olds (2000) vão descrever esse desejo pelo 
novo como emoção intensificada, que pode ser expressa por meio de rebelião e de comportamento antissocial. Experiências vividas com emoção causam efeito sobre as atitudes; assim, com o decorrer do tempo, valores e comportamentos fazem da tensão emocional um produto da má saúde física e mental. O desajustamento de personalidade conduz à impaciência, à não cooperação e ao retraimento.

Durante a elaboração das histórias, a desilusão amorosa e a dificuldade de relacionamento social acarretaram carência afetiva como causa da depressão. Aqui as representações sociais estão associadas à esfera psicoafetiva, e o desafeto ou falta de amor se encontra presente. Nessa perspectiva, o grupo e o relacionamento romântico têm um papel importante nos processos de desenvolvimento psicológico e social. Uma vez que o adolescente não possui uma referência pessoal formada, procura no grupo o auxílio para se autoafirmar, tendo como principal objetivo a uniformidade de saber quem é e a necessidade de pertença. Assim, há um processo de identificação maciça, em que todos se identificam entre si e o grupo e o parceiro(a), e isso pode ocasionar dependência ao adolescente (Bandim, Roazzi, \& Doménech, 1998). Portanto, os púberes, ao relacionar a causa da depressão com o isolamento social e a desilusão amorosa, deixam evidente o fator patológico dessa relação. Nessa perspectiva, os autores ainda relatam que, na adolescência, alguns comportamentos afetam a autoconfiança dos jovens, e essa falta de confiança pode levar a devaneios, à vivência da figura do herói sofredor, incompreendido, mal julgado e maltratado. Diante de frustrações, o púbere tem a crença de que nada vale a pena, o que pode ocasionar ameaças de suicídio. Dalgalarrondo (2008) ainda explica que a afetividade se caracteriza particularmente por sua dimensão de reatividade, ou seja, ligandose esse sentimento ao desenho, vê-se a capacidade de o adolescente ser influenciado afetivamente por estímulos externos, o que faz com que entristeça em decorrência de uma frustração amorosa.

Gunnell (2000) relata que, no início da adolescência, tem-se o desenvolvimento do pensamento abstrato, o que acarreta uma concepção mais clara do fenômeno da morte. Em adolescentes com sintomatologia depressiva, esses pensamentos costumam apresentar alta letalidade, característica essa presente na terceira categoria - depressão associada a ideias mórbidas. O pensamento suicida e o próprio ato em adolescentes já são motivos de pesquisa por décadas no Brasil. Feijó, Salazar, Bozko, Candiago, Ávila et al. (1996), investigando essa mesma temática entre adolescentes na faixa de 13 a 20 anos de idade, que foram atendidos no Pronto Socorro do Hospital de Clínicas de Porto Alegre-RS por tentativa de suicídio, encontraram os seguintes resultados: $88 \%$ das tentativas foram causadas por intoxicações; $84,4 \%$ dos casos ocorreram com garotas; $47 \%$ já haviam tido uma tentativa de suicídio anterior, e 28\% apresentaram diagnóstico de depressão maior. Em pesquisa realizada com estudantes universitários na cidade de João Pessoa, por Vieira e Coutinho (2008), sobre depressão e suicídio, as pesquisadoras perceberam uma associação entre os dois fenômenos. $\mathrm{O}$ suicídio era objetivado por esses estudantes pelo elemento morte, que representa uma fuga, uma saída escolhida pelo indivíduo face às adversidades advindas do meio externo.

Em suma, os resultados demonstram que, de modo geral, os desenhos e as produções semânticas trazidas pelos adolescentes são o resultado não só dos problemas que 
circundam seu posicionamento na sociedade como também de suas vivências integradas à circulação da informação da doença em seu meio de pertença, de suas imagens e de suas representações sociais.

\section{Considerações finais}

Ao se penetrar na instituição escolar, percebeu-se a ambiguidade da temática, uma vez que a sintomatologia da depressão tanto pode ser vista como característica dessa fase de vida (adolescência) como também pode ser classificada como doença. Com a pesquisa, verificou-se um índice considerável dessa patologia. Junto a outros estudos nessa área, que podem ser verificados por meio do arcabouço teórico já suscitado, tem-se visto um crescimento desse quadro entre os adolescentes, fato a que se deve dar atenção, uma vez que o aumento do índice passa a ser um problema de saúde pública, merecendo uma intervenção das próprias instituições de ensino, da família e dos sistemas de saúde. Observou-se no estudo uma relação entre a pontuação do CDI e as representações sociais, tendo em vista que todos os participantes aqui inseridos apresentaram sintomas de depressão moderada, o que demonstra uma coesão entre os conteúdos levantados pelos adolescentes e seus sintomas e as interpretações destes pelos adolescentes. Outro fator também demarcado foi o sentimento de tristeza que atravessou todas as representações, mesmo não sendo o enfoque primário suscitado pelos participantes. Contudo, ressalta-se que esses sentimentos não se detiveram apenas na esfera psicoafetiva, pois eles transbordaram e englobaram as relações sociais e cognitivas dos púberes. Percebeu-se, portanto, que a temática foi multifatorial, ressaltando vários aspectos, fato esse que pode ser considerado pelo amadurecimento cognitivo e pelas informações adquiridas no meio de pertença dos jovens, o que os possibilita associar as suas próprias causas a fatores do seu convívio.

Em suma, foram abordados aspectos relevantes ao tema, podendo-se, com as histórias e figuras dos adolescentes, caracterizar suas representações acerca dos efeitos da depressão. Pode-se atentar com isso que tem mudado, no decorrer dos anos, o modo de ver e conceituar a depressão nessa faixa etária, demonstrando com isso que a sociedade não é estática, e nem o próprio adolescente que nela está inserido. Porém fazem-se necessárias não só averiguações mais detalhadas entre os tipos de depressão e a percepção que o adolescente tem sobre as suas vivências como também a demarcação das características culturais e sociais que possam determinar de forma mais efetiva $o$ desenvolvimento da patologia.

O sistema educacional é um aliado importante para a solidificação de ações que promovam a saúde e a quebra de paradigmas, principalmente os relacionados a preconceitos e tabus. Essas atitudes devem ser direcionadas ao fortalecimento das capacidades dos indivíduos e à tomada de decisões favoráveis à saúde física e mental. Desse modo, cabe ao sistema educacional um papel mais representativo na percepção das mudanças de comportamento dos discentes, atentando para as manifestações da sintomatologia depressiva nos adolescentes e buscando seus significados psicoafetivos, culturais e sociohistóricos, o que contribuirá para a eficácia do diagnóstico e da intervenção para melhor qualidade de vida nessa fase. 


\section{Karla Carolina Silveira Ribeiro*}

Doutoranda em Psicologia Social pela Universidade Federal da Paraíba, Paraíba, PB - Brasil.

\section{Emily da Silva Nascimento}

Mestranda em Psicologia, pesquisadora do Grupo de Pesquisa Marxismo \& Educação -Universidade Federal do Rio Grande do Norte, Rio Grande do Norte, RN - Brasil.

E-mail: emilynascimento@yahoo.com.br

\section{Maria da Penha de Lima Coutinho}

Pós-Doutorado em Psicologia pela Universidade Aberta de Lisboa-Portugal/ Programa de Pós-Graduação em Psicologia Social e coordenadora do Núcleo de Pesquisa Aspectos Psicossociais de Prevenção e Saúde Coletiva - UFPB E-mail: penhalcoutinho@yahoo.com.br

*Endereço para envio de correspondência:

Rua Enfermeira Ana Maria Barbosa de Almeida, 426/402, Edifício Ellus, Bancários

João Pessoa, PB - Brasil - CEP 58 052-270.

E-mail: karlacribeiro@yahoo.com.br 


\section{Referências}

Abric, J. C. (2001). O estudo experimental das representações sociais. In D. Jodelet (Ed.), As representações sociais (pp. 4863). Rio de Janeiro: Ed. da UERJ.

American Medical Association. (2002). Guia essencial de depressão. São Paulo: Aquariana.

American Psychiatric Association. (2000). DSM-IV - Diagnostic and Statistical Manual of Mental Disorders (4rd ed. rev.) Washington, DC: Author.

Anadón, M., \& Machado, P. B. (2003). Reflexões teóricas: metodológicas sobre as representações sociais. Bahia: Ed. da UNEB.

Aragão, T. A., Coutinho, M. P. L., Araujo, L. F., \& Castanha, A. R. (2009). Uma perspectiva psicossocial da sintomatologia depressiva na adolescência. Ciência \& Saúde Coletiva, 14(2), 395-405.

Assis, S. G., Avanci, J. Q., Silva, G. M. F. P., Malaquias, J. V., Santos, N. C., \& Oliveira, R. V. C. (2003). A representação social do ser adolescente: um passo decisivo na promoção da saúde. Ciência \& Saúde Coletiva, 8(3), 669-679.

Bahls, S. C. (2001). Medicamentos antidepressivos e insônia. Revista Temas: Teoria e Prática do Psiquiatra, 31.

Bahls, S. C. (2002). Aspectos clínicos da depressão em crianças e adolescentes. Jornal de Pediatria, 78(5), 359-366.

Bardin, L. (2000). Análise quantitativa e análise qualitativa: análise de conteúdo (70a ed.). Lisboa: LDA.

Bandim, J. M., Roazzi, A., \& Domenéch, E. (1998). Rendimento escolar em crianças com sintomas depressivos. Jornal Brasileiro de Psiquiatria, 47(7), 353-360.

Barbosa, G. A., Dias, M. R., Gaião, A. A., \& Lorenzo, W. C. G. (1996). Depressão infantil: um estudo de prevalência com CDI. Revista de Neuropsiquiatria da Infância e Adolescência, 4(3), 36-40.

Barros, A. P. R. (2005). As representações sociais da depressão em adolescentes no contexto escolar. Dissertação de Mestrado em Psicologia Social, Universidade Federal da Paraíba, João Pessoa, PB.

Barros, A. P. R., Coutinho, M. P. L., Araujo, L. F, \& Castanha, A. R. (2006). As representações sociais da depressão em adolescentes no contexto do ensino médio. Estudos de Psicologia, 23(1), 19-28.

Bock, A. M. B., Furtado, O., \& Teixeira, M. L. T. (1999). Psicologias: uma introdução ao estudo de psicologia (13a ed.). São Paulo: Saraiva.

Brêtas, J. R. S. (2003). Núcleo de estudos da criança e do adolescente. São Paulo: NECAd, Universidade Federal de São Paulo.

Brasil. (1990). Lei no 8.069, de 13 de julho de 1990. Dispõe sobre o Estatuto da Criança e do Adolescente e dá outras providências. Diário Oficial da União.

Campos, D. M. S. (2005). O teste do desenho como instrumento de diagnóstico da personalidade (37a ed.). Petrópolis, RJ: Vozes.

Coutinho, M. P. L. (2001). Depressão infantil: uma abordagem psicossocial. João Pessoa: Universitária.

Coutinho, M. P. L., Contiés, B., Araújo, L. F., \& Sá, R. C. N. (2003). Depressão, um sofrimento sem fronteiras: representações sociais entre crianças e idosos. Revista Semestral da Área de Psicologia, 8(2), 183-192.

Coutinho, M. P. L. (2005). Depressão infantil e representação social. João Pessoa: Universitária.

Crivelatti, M. M. B., Durman, S., \& Hofstatter, L. M. (2006). Sofrimento psíquico na adolescência. Texto contexto Enfermagem, 15, 64-70.
Cunha, J. (2001). Manual em português das Escalas Beck. São Paulo: Casa do Psicólogo.

Dalgalarrondo, P. (2008). Psicopatologia e semiologia dos transtornos mentais (2a ed.). Porto Alegre: Artmed.

Dultra, E. M. S. (2001). Depressão e suicídio em crianças e adolescentes. Mudanças: Psicoterapia e Estudos Psicossociais, 9(15), 27-35.

Feijó, R. B., Salazar, C. C., Bozko, M. P., Candiago, R. H., Ávila, S. et al. (1996). O adolescente com tentativa de suicídio: características de uma amostra de 13 a 20 anos atendida em emergência médica. Jornal Brasileiro de Psiquiatria, 45(11), 657-64

Gunnell, D. J. (2000). The epidemiology of suicide. International Review of Psychiatry, 12, 21-26.

Holmes, D. S. (2001). Psicologia dos transtornos mentais. Porto Alegre: Artes Médicas.

Jodelet, D. (2001). As representações sociais: um domínio em expansão. In D. Jodelet (Ed.), As representações sociais (pp. 17-44). Rio de Janeiro: Ed. da UERJ.

Justo, J. S. (2005). O "ficar" na adolescência e paradigmas de relacionamento amoroso da contemporaneidade. Revista do Departamento de Psicologia - UFF, 17(1), 61-77.

Kazdin, A. E., \& Marciano, P. L. (1998). Childhood and adolescent depression. In E. Mash \& R. Barkley (Eds.), Treatment of childhood disorders (pp. 88-104). New York: The Guilford Press.

Kovacs, M. (1992). Children Depression Inventory CDI: Manual. New York: Multi-Health Systems.

Monteiro, F. R., Coutinho, M. P. L., \& Araújo, L. F. (2007). Sintomatologia depressiva em adolescentes do ensino médio: um estudo das representações sociais. Psicologia: Ciência e Profissão, 27(2), 224-235

Moscovici, S. (2003). Representações sociais: investigações em psicologia social. Petrópolis, RJ: Vozes.

Nóbrega, S. M. (2001). Sobre a teoria das representações sociais. In A. S. Moreira (Ed.), Representações sociais: teoria e prática (pp. 55-87). João Pessoa: Universitária.

Newcombe, N. (1999). Desenvolvimento infantil: abordagem de Mussen. Porto Alegre: Artmed.

Papalia, D. E., \& Olds, S. W. (2000). Desenvolvimento humano. Porto Alegre: Artes Médicas.

Peluso, E. T. P., \& Blay, S. L. (2008). Percepção da depressão pela população da cidade de São Paulo. Revista de Saúde Pública, 42(1), 41-48.

Sá, C. P. (1996). Núcleo central das representações sociais. Petrópolis, RJ: Vozes.

Sadock, B. J., \& Sadock, V. A. (2007). Compêndio de psiquiatria: ciência do comportamento e psiquiatria clínica (9a ed.). Porto Alegre: Artmed

Trinca, W. (1976). Investigação clínica da personalidade: o desenho livre como estímulo de apercepção temática. Belo Horizonte: Interlivres.

Tsu, T. A., \& Borges, W. (1991). Vício e loucura: estudo de representações sociais de escolares sobre doença mental, através do uso do procedimento de desenhos-estórias com tema. Boletim de Psicologia, 10(4), 47-55.

Vieira, K. F. L., \& Coutinho, M. P. L. (2008). Representações sociais da depressão e do suicídio elaboradas por estudantes de psicologia. Psicologia: Ciência e Profissão, 28(4), 714-727.

Winnicott, D. W. (1991). O brincar e a realidade. São Paulo: Imago. 